SURGICAL INNOVATIONS AND INSTRUMENTATION

Michael Joseph C. David, MD'

Antonio H. Chua, MD ${ }^{1,2}$

'Department of Otorhinolaryngology

Head and Neck Surgery

Jose R. Reyes Memorial Medical Center

2Department of Otorhinolaryngology Head and Neck Surgery

University of the East Ramon Magsaysay

Memorial Medical Center
Correspondence: Michael Joseph C. David, MD Department of ENT-HNS

Jose R. Reyes Memorial Medical Center

San Lazaro Compound

Rizal Avenue, Sta. Cruz, Manila 1003

Philippines

Phone/Fax: (632)743 6921

Reprints will not be available from the author.

No funding support was received for this study. The authors signed disclosures that they have no proprietary or financial interest with an organization that may have a direct interest in the subject matter of this manuscript, or in any product used or cited in this study.

Presented at Surgical Instrumentation Poster Contest ( $1^{\text {ST }}$ Place) Philippine Society of Otolaryngology Head and Neck Surgery $52^{\text {nd }}$ Annual Convention, Dusit Thani Hotel, Makati City

November 29-30, 2008

\section{The Flexmount Ringlight: An Inexpensive Lighting Solution for Intraoral Photodocumentation}

ABSTRACT
Objective: To fabricate an inexpensive, reproducible and portable ringlight with flexible, quick-release mount for use with point-and-shoot consumer digital cameras in intraoral photodocumentation.

\section{Methods:}

Design: Instrumentation

Setting: Tertiary Care Hospital

Procedure: A commercially-available battery-powered mountaineer's LED (Light Emitting Diode) headlight was converted into a portable ringlight with a flexible, quick-release mount for intraoral photodocumentation.

Results: The Flexmount Ringlight delivered an even and white illumination of the oral cavity and oropharynx at a working distance of more than $5 \mathrm{~cm}$ from the subject in focus. It resulted in sharper pictures due to its constant illumination that assisted the camera's autofocus system in getting accurate focusing intraorally. It also allowed the camera to use smaller apertures that have put more elements in focus and faster shutter speeds that have markedly reduced motion blur.

Conclusion: The Flexmount Ringlight is an inexpensive, easy-to-assemble and portable ringlight that can be used in point-and-shoot consumer digital cameras. Its constant and even illumination resulted in reproducible, sharp, shadowless photographs of the oral cavity and oropharynx.

Key words: ringlight, flexmount, intraoral photodocumentation

Medical photodocumentation has been acknowledged as an indispensible tool in the practice of Medicine and Surgery since Gurdon Buck's first published article with preoperative illustrations of his patient in 1845.' Photographs, both film and digital, have detailed patient conditions, accurately documented surgical procedures and augmented verbal and written descriptions of communication with patients and colleagues. ${ }^{2}$ They have served as invaluable teaching tools and have also provided 


\section{SURGICAL INNOVATIONS AND INSTRUMENTATION}

valuable documentation in medicolegal cases.

Digital cameras have become so commonplace nowadays that most physicians own or have one integrated into their cellular phones, portable notebook computers and even personal music players. But not all digital cameras are created equal. Proper and formal medical photography requires the clinician to avail of the best, or at least, the optimal camera and lighting setup. ${ }^{3}$ This includes at least a $35 \mathrm{~mm}$-equivalent or a digital single lens reflex (SLR) sized camera sensor, macro-capable lenses and specialized lighting such as ringflashes or macro lights for intraoral photography. These provide the best setting for accurate, reproducible and well-detailed documentation, but such equipment may prove too expensive or superfluous for most private practitioners and residents-in-training.

Point and shoot consumer-grade cameras are the next best option, with most having automated white balancing, exposure and flash intensity controls, capable of taking acceptable gross clinical photographs. Special settings such as intraoral photography may prove much of a challenge with these pointand-shoot camera models which usually employ off-center and built-in flashes. The illumination that these flashes provide cannot cover much of the oral cavity and oropharynx adequately. Ringflashes and lights, and macro lights (Figure 1) have been designed to produce an even and virtually shadowless field of view for intraoral as well as facial photography, much like the head mirror of the otorhinolaryngologist.

However, these lighting systems sold at retail prices of P18,000 and above, ${ }^{5}$ (Figure $1 a-b$ ) are even more expensive than most point-and-shoot cameras, making them virtually impractical.

This paper proposes an inexpensive lighting solution to taking acceptable, reproducible, intraoral photographs - the Flexmount Ringlight. Our objective was to fabricate an inexpensive, reproducible and portable ringlight with a flexible, quick- release mount attached to point-and-shoot consumer digital cameras that will be acceptable for intraoral photodocumentation.

\section{Materials:}

\section{MATERIALS AND METHODS}

(1) 12-white LED (light emitting diode) headlight with tilting base (Ren Guang Company, China)

(2) Flexible monopod with suction cup base and quick release plate (CDR King, China)

(3) Mini Hand Drill (Möller, Germany)

(4) Perforating and Grinding burrs (Möller, Germany)

(5) Soldering iron set (Newstar-Chitlink Electrical International, China)

(6) Round nosed pliers

(7) Wire cutter/stripper

(8) $1 / 2$ inch wood screw

(9) Phillips 6x75mm Screwdriver

\section{Procedure:}

1. The 12- white LED headlight with adjustable mount was disassembled (Figure 2a-b).

2. The middle four LED bulbs and extra resistors were removed as shown (Figures 3a-b). This particular headlight featured three colored running LEDs around the sides. These were removed as well. Note the circular configuration of the etching in the circuit board. This allowed for a $33-\mathrm{mm}$ hole to be cut into the middle of the board within the innermost main concentric etching using the mini drill (Figure 4).

3. Corresponding holes were also cut into the front reflector component and the back plate (Figure 5a).

4. The wires and one $2.5 \mathrm{ohm}$ resistor were resoldered (Figure 5b, Appendix A) to form a parallel circuit with the power supply (3 1.5V AA batteries).

5. The headlight was then reassembled.

6. The suction cup was removed from the flexible monopod. The plastic base of the monopod was attached, using a screw and rubber washers, onto the base of the headlight as shown (Figures 6a-b).

\section{Device Operation:}

To use the Flexmount Ringlight, 3 1.5V AA batteries should be loaded into the battery chamber. A point-and-shoot camera with macro shooting capabilities is mounted on the quick-release plate (Figure 7a-b). The flexible arm is bent back to position the camera at the back of ringlight.

The camera is set on shooting mode. With the aid of the LCD (Liquid Crystal Display) viewer, the lens barrel is inserted into the ring and the zoom is adjusted to remove any vignetting caused by parts of the Flexmount Ringlight within the angle of view of the camera. Recommended shooting settings: MACRO MODE, FLASH OFF, AUTO ISO, CENTER AF (autofocus), IMAGE STABILIZATION/VIBRATION REDUCTION ON, and smallest aperture (high $\mathrm{f}$ number) if available. The aperture and exposure settings are adjusted as needed.

When taking intraoral pictures, the camera- Flexmount Ringlight setup is positioned at a minimum working distance of $6 \mathrm{~cm}$ from the patient's face. The maximum working distance is determined by the camera's macro focus range. The average point-and-shoot usually has macro focus range within $10-50 \mathrm{~cm}$ from the subject.

The camera is held by the right hand while the left hand holds the Flexmount arm like a gun as demonstrated in Figures 8a-c.

When using smaller compact cameras, e.g. Canon's Ixus or Sony's Cybershot models, the Flexmount Ringlight may be used without attaching the camera on the monopod. 


\section{SURGICAL INNOVATIONS AND INSTRUMENTATION}

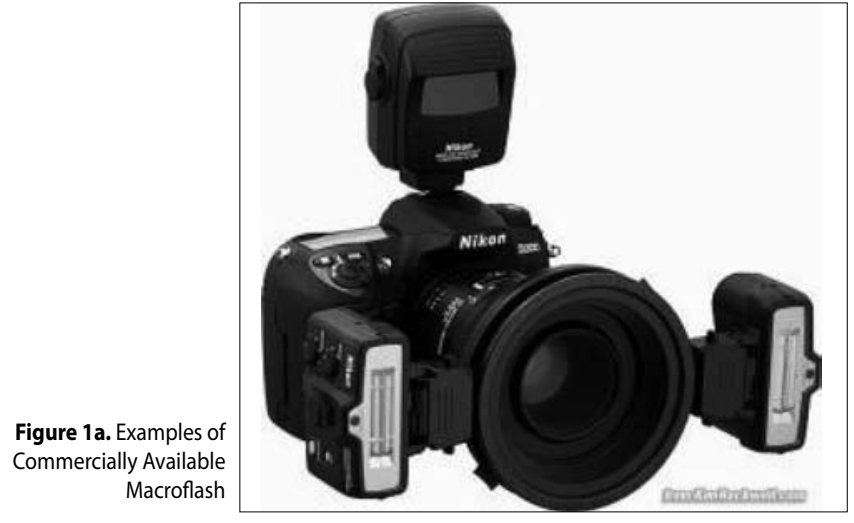

Macroflash
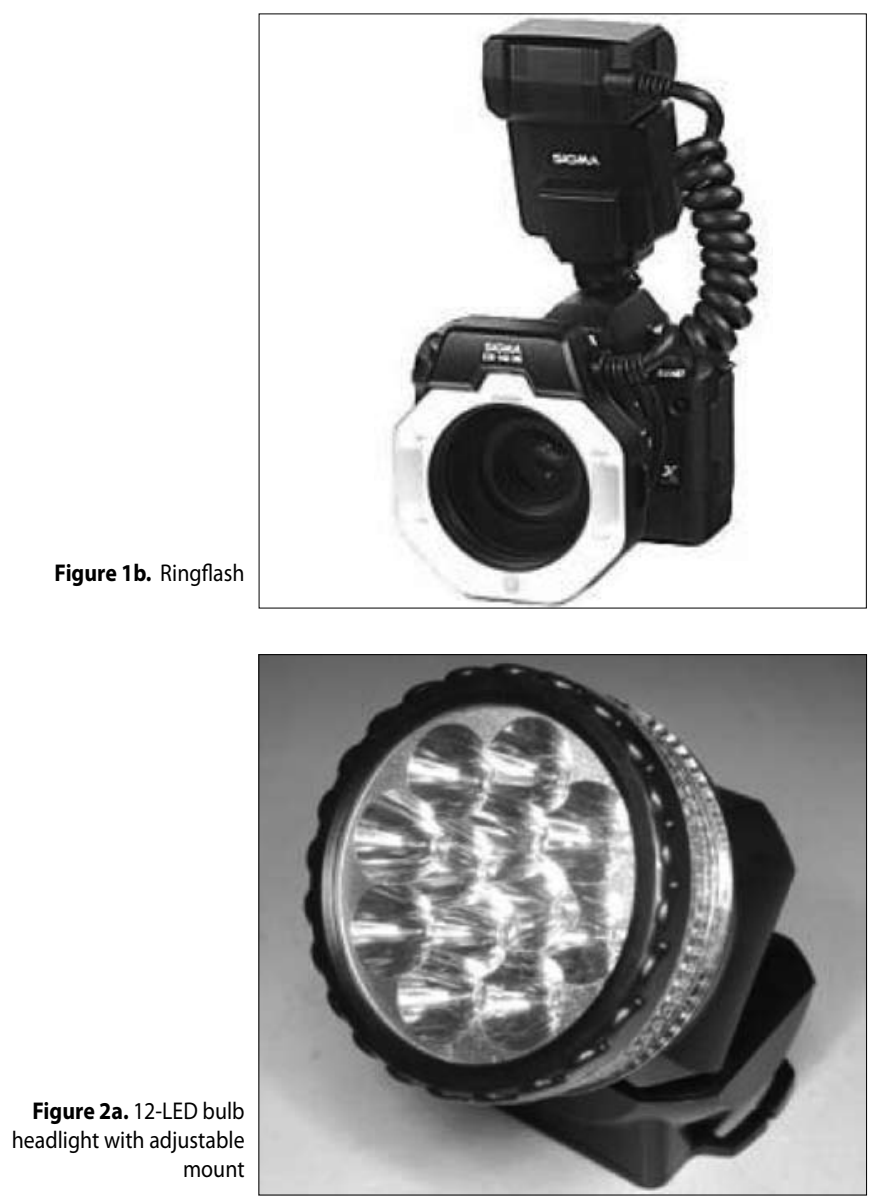
mount

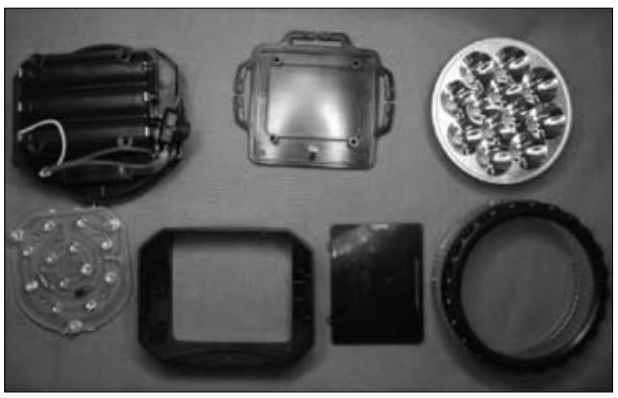

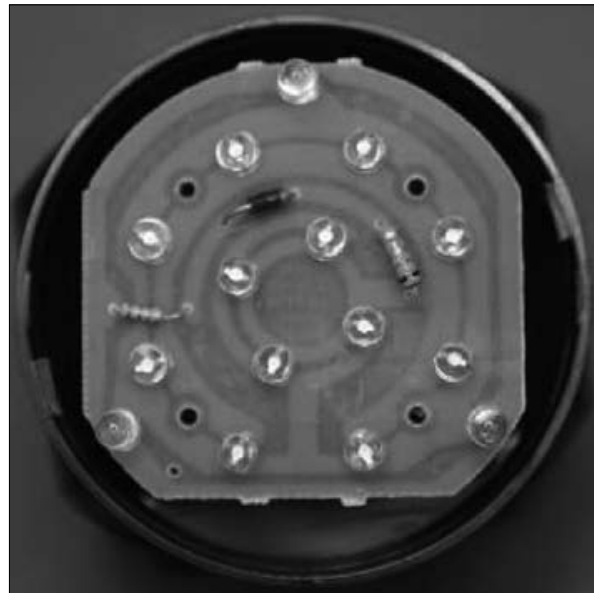

Figure 3a. Closeup view of the circuit board

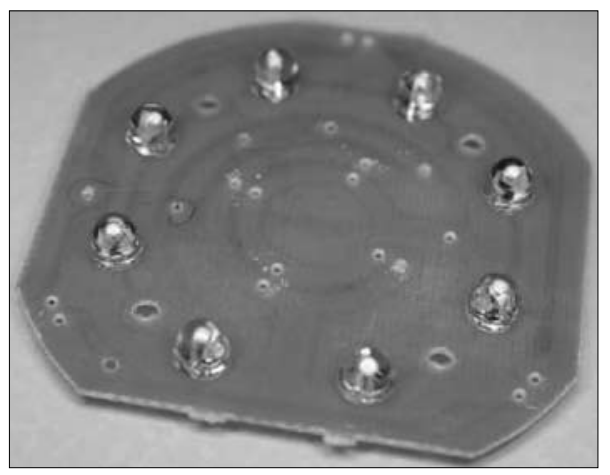

Figure $3 \mathbf{3 b}$. Circuit board stripped of unneeded components

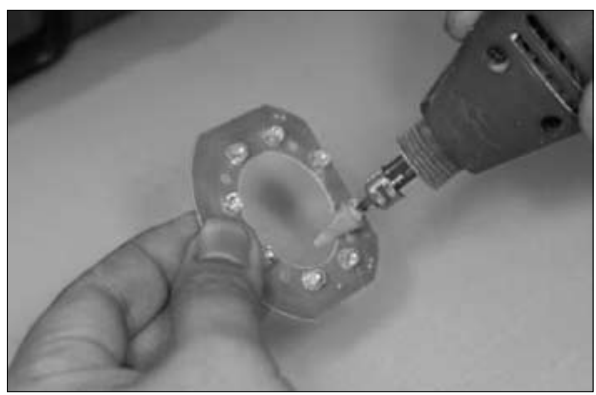

Figure 4. A 33mm hole cut was into the circuit board

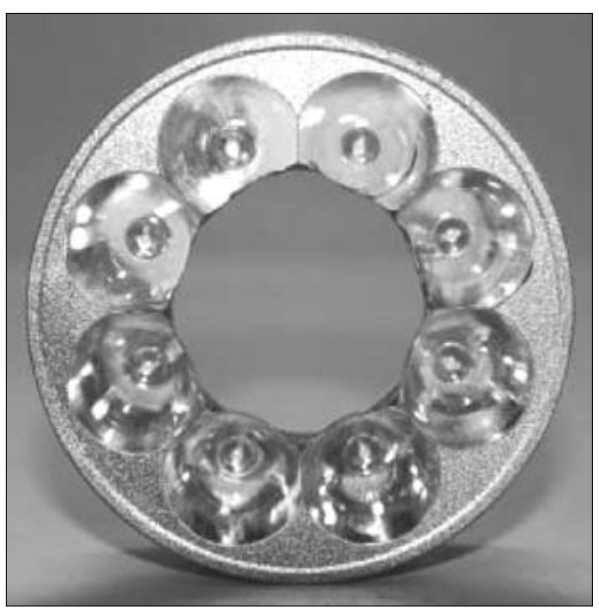

Figure 5a. Corresponding 33mm hole cut into the front reflector 


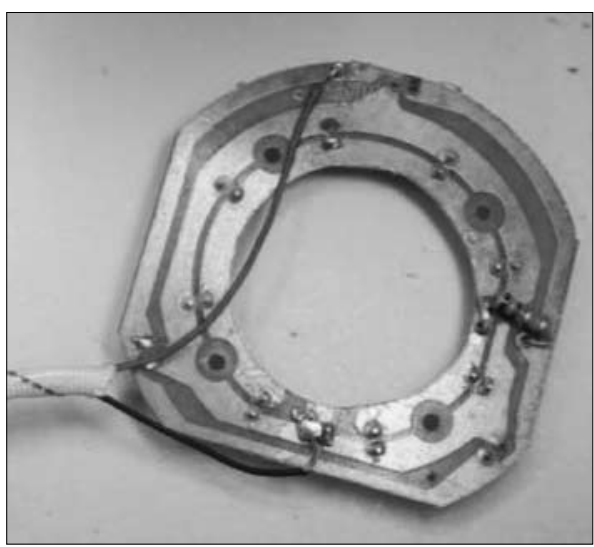

Figure 5b. Resoldering of wires and resistor on the circuit board

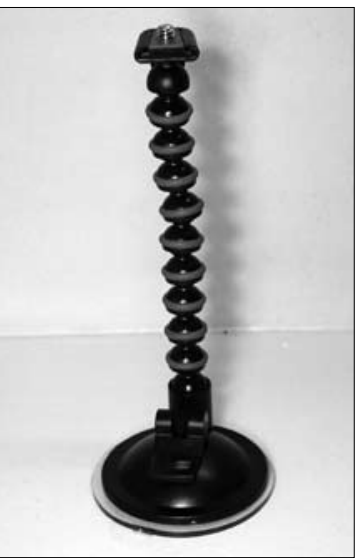

Figure 6a. Flexible monopod with suction cup base

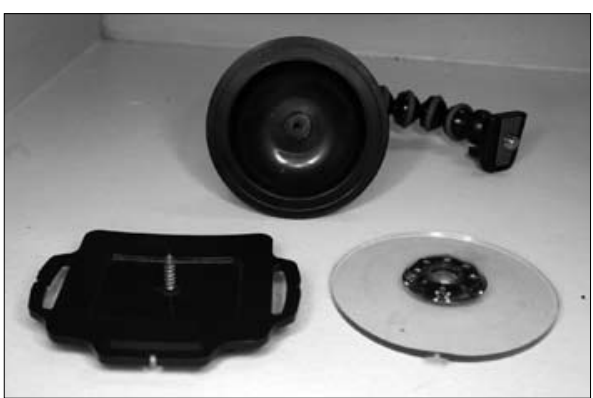

Figure $6 \mathrm{~b}$. Suction cup removed, and monopod base attached to headlight

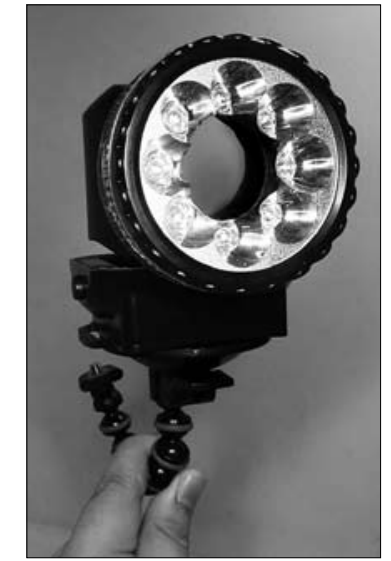

Figure $\mathbf{6 c}$. Completed Fleximount Ringligh

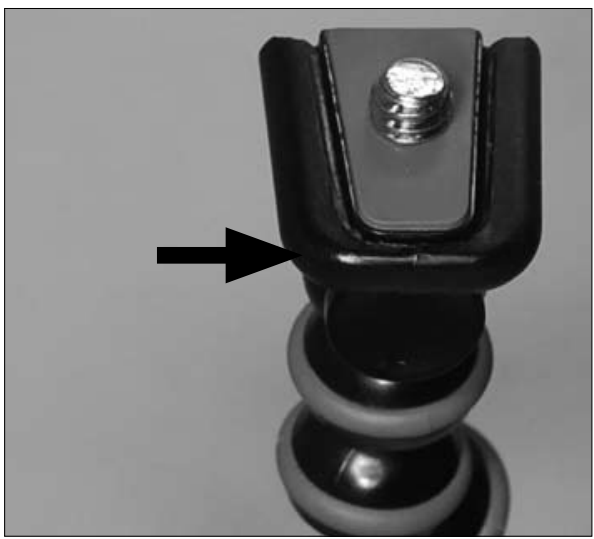

Figure 7a. Quick Release Plate (arrow)

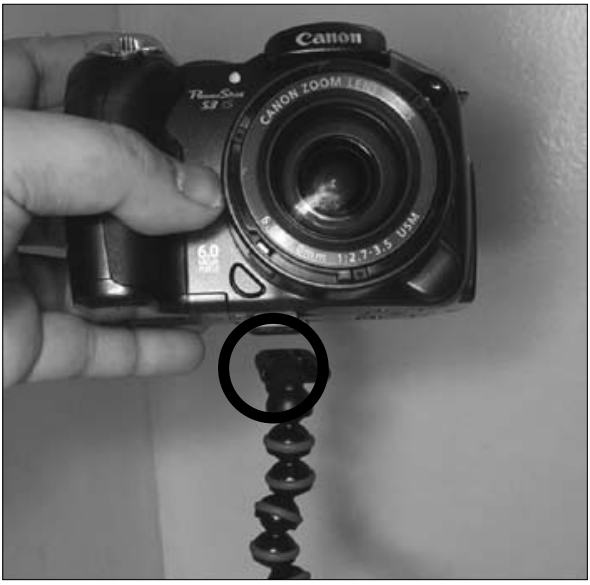

Figure 7b. Camera with attached quick release plate (circle)

\section{RESULTS}

The Flexmount Ringlight system weighed approximately 150 grams excluding batteries and camera. Total production cost was P270 (Appendix B). Total assembly time was two hours.

The Flexmount Ringlight was tested on a 6 megapixel pointand-shoot digital camera (Canon Powershot S3-IS) with macro shooting capability. Comparisons of intraoral photographs taken using the camera's built-in flash and using the Flexmount Ringlight are shown below (Figure 9).

\section{DISCUSSION}

Due to the more superior position of the built-in flash in relation to the line of sight of the lens, intraoral pictures taken without the Flexmount Ringlight caused the upper lip and teeth to produce a shaded portion over the palate. The Flexmount Ringlight delivered a constant and even white illumination of the oral cavity and oropharynx at working distances more than $5 \mathrm{~cm}$ from the subject in focus. The Flexmount Ringlight should not be used at shorter distances as the beams of the individual LEDs become more focused, producing distinct circles of light (Figure 10a.) 
SURGICAL INNOVATIONS AND INSTRUMENTATION
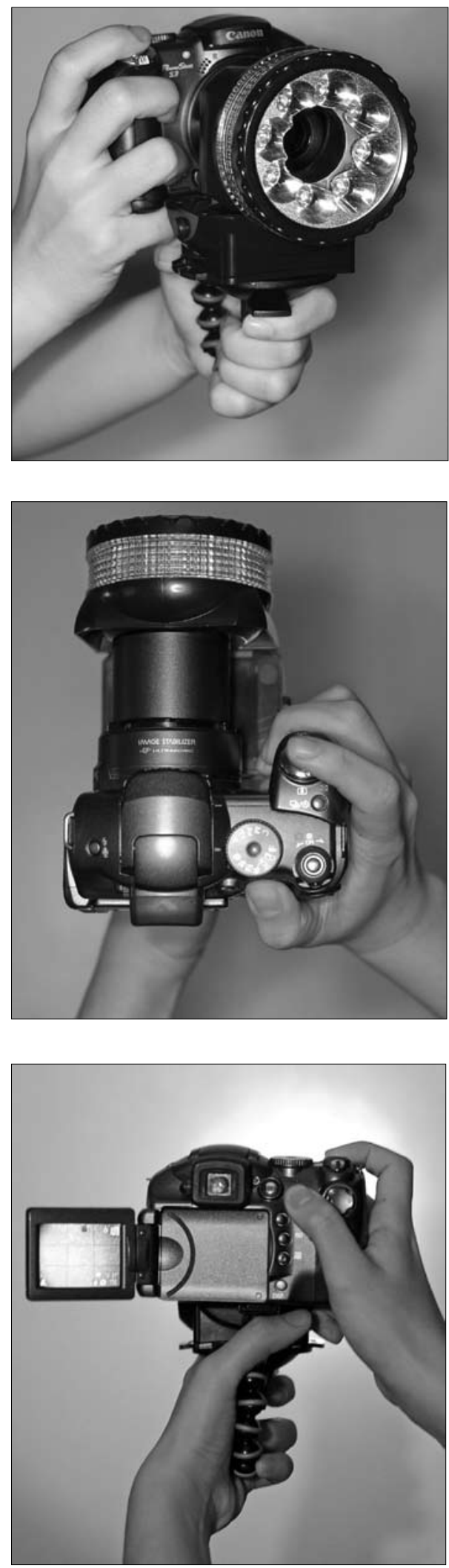

Figures 8 a-c. Handling of a point-and-shoot camera (Canon Powershot S3-IS) with attached Flexmount Ringlight

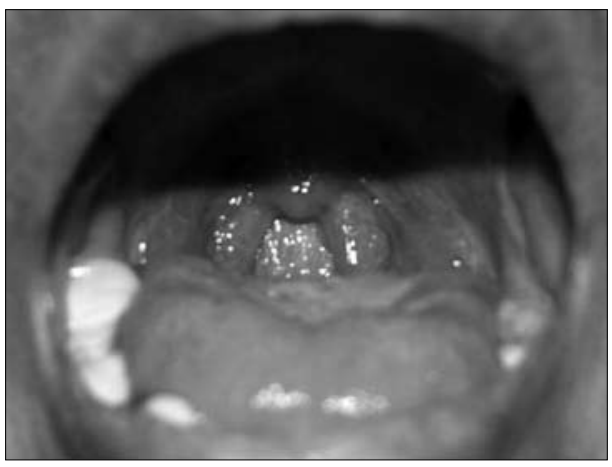

Figure 9a. Intraora

Photograph taken with the built-in flash

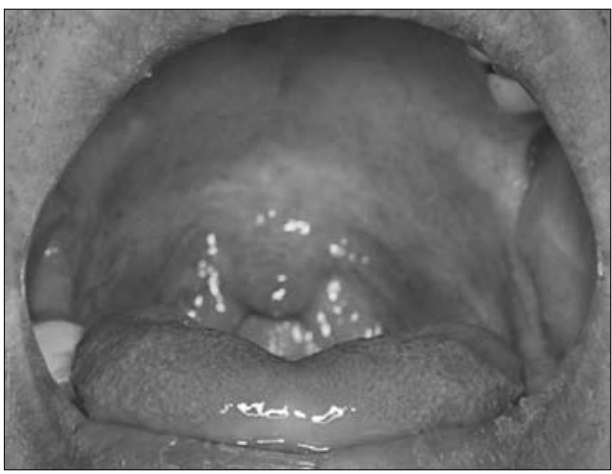

Figure 9b. Taken with conventional ringflash

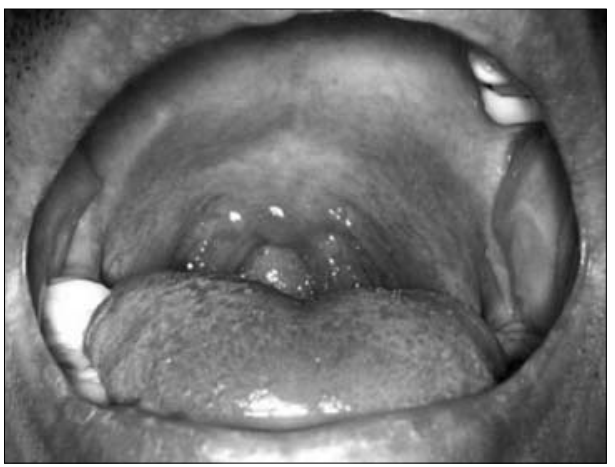

Figure 9c. Taken with FLEXMOUNT RINGLIGHT

As LEDs emit light contained in a limited color spectrum, it is to be expected that pictures will appear as if taken in unnatural colors. Appropriate white balance adjustments (Flash or Daylight setting in the test camera) may be needed to get the desired color temperature and hue.

Maintaining even lighting from an array of LEDs is crucial. This was achieved by inserting a $2.5 \mathrm{ohm}$ resistor in the circuit. This resulted in a constant light intensity and prevents the LED bulbs from burning out ${ }^{6}$.

As indicated in the original packaging, the headlight used in this project was rated to run for up to 50 hours on three $1.5 \mathrm{~V} A \mathrm{~A}$ alkaline batteries ( $3 \mathrm{~V}$ total), and the LEDs used have a lifespan of 100,000 hours. We expect the modified headlight with 4 less LEDs to light to run for longer periods. 
The Flexmount Ringlight also resulted in sharper pictures. The constant and even illumination it provides assisted the camera's autofocus system in getting accurate focusing when taking intraoral pictures. Commercially available cameras usually have focus assist lamps that may be too laterally located for them to be of use in narrow fields such as the oral cavity. By providing bright lighting, the Flexmount Ringlight allowed the camera to use smaller apertures and faster shutter speeds, thus allowing more elements to be put into focus and minimizing motion blur as well.

The Flexmount Ringlight is an inexpensive, easy-to-assemble and portable ringlight attached to point-and-shoot consumer digital cameras. Its constant and even illumination resulted in reproducible, sharp, shadowless photographs of the oral cavity and oropharynx.

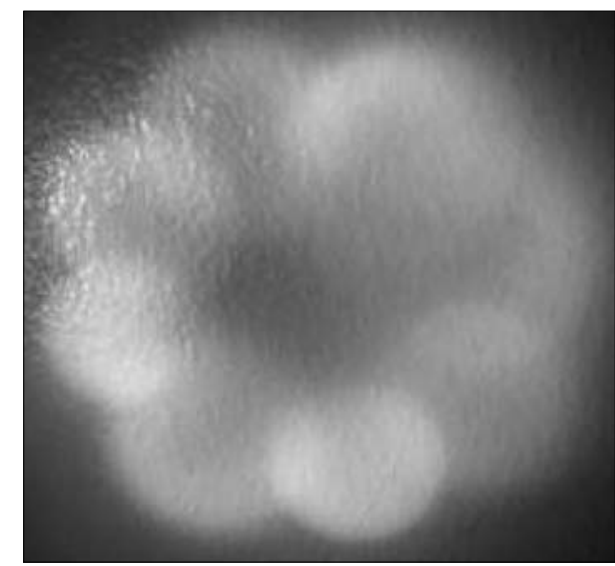

Figure 10a. Light produced by the ringlight at a working distance of $5 \mathrm{~cm}$

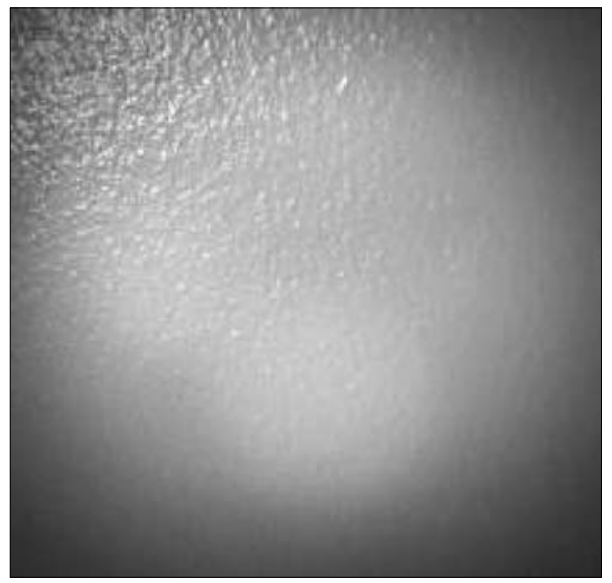

Figure 10b Light produced at a working distance of $10 \mathrm{~cm}$

\section{Appendix A Circuit board Schematics of the Flexmount Ringlight}

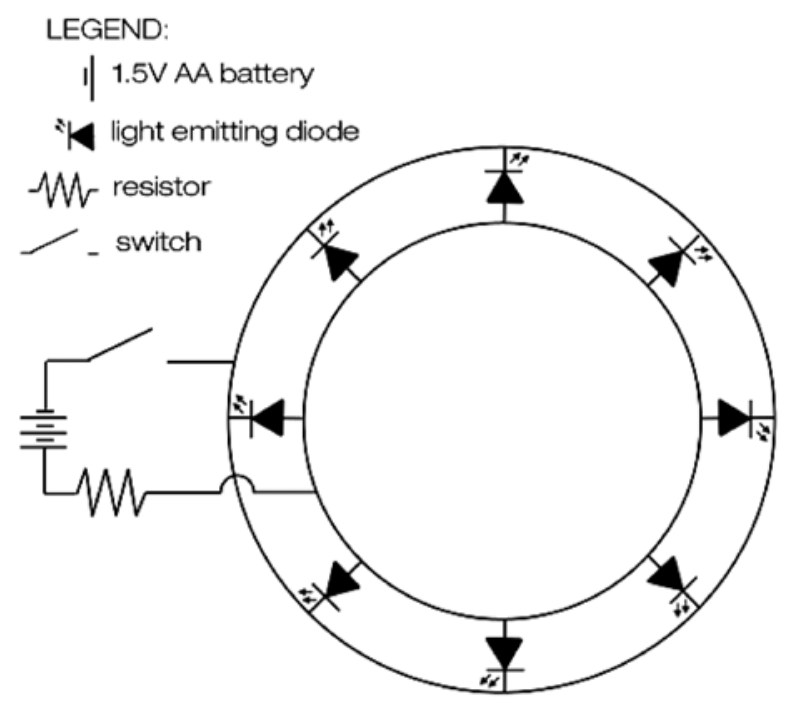

\section{Appendix B \\ Materials Used and Costing for the Fabrication of the Flexmount Ringlight}

\begin{tabular}{lcr}
\multicolumn{1}{c}{ Item } & $\begin{array}{c}\text { Materials used* } \\
\text { Quantity }\end{array}$ & Cost \\
$\begin{array}{l}\text { 12-white LED } \\
\text { (light emitting diode) headlight } \\
\text { with adjustable mount }\end{array}$ & $1 p c$ & P 190.00 \\
$\begin{array}{l}\text { flexible monopod with suction cup } \\
\text { base and quick release plate }\end{array}$ & $1 p c$ & P 80.00 \\
$\begin{array}{l}\text { Miscellaneous items: Solder wire, } \\
\text { solder flux, wood screw }\end{array}$ & $\mathrm{P} 10.00$ \\
Total cost excluding batteries & & $\mathrm{P} 280.00$ \\
\hline
\end{tabular}

1. Rogers B. The first pre- and postoperative photographs of plastic and reconstructive surgery: contributions of Gurdon Buck (1807-1877). Aesthetic Plast Surg 1991; 15(1):19-33.

2. Haynes DS Moore BA Roland P Olson GT. Digital microphotography: a simple solution. Laryngoscope2003; 113(5): 915-919.

3. Yavuzer R, Stefani S, Jackson I, Guidelines for Standard Photography in Plastic Surgery. Ann Plast Surg 2001; 46(3): 293-300.

4. Torrecillas D, Soler-González J, Rodríguez-Rosich A. Digital photography in the generalist's ofce. Can Med Assoc J 2006; 175(12): 1519-1521.

5. DP Online Store [homepage on the Internet]. Manila: DP Online Store; c2008 [cited 2008 Nov 10]. Available from: http://dponline.com.ph/

6. Gibilisco S, Teach Yourself Electricity and Electronics. 4th Ed, New York: McGraw Hill; 2006.
} 